\title{
Çarpma yükü etkisinde sandviç plakların şekil optimizasyonu
}

\author{
Sedat SAVAŞ, Dursun BAKIR* \\ Firat Üniversitesi, Inşaat Mühendisliği Bölümü, Elazı ̆̆ \\ (ORCID: 0000-0003-2466-3514) (ORCID: 0000-0001-6398-0497)
}

\begin{abstract}
$\ddot{O} \mathbf{z}$
Çarpma yükü altındaki plakların davranışı statik yüklemelerin aksine farklılık göstermektedir. Cismin plağa çarpma anında ve cismin plaktan teması kestikten sonrada plaktaki gerilme dağılımları değişmektedir. Yaptı̆̆ımız çalışmada bu gerilme değişimlerini hesaba katarak iki plak levhası arasına konulan çekirdek malzemesi geometrisinin şekil optimizasyonu amaçlanmıştır. Bu amaçla önce mekanik özellikleri bilinen polipropilen sandviç levha üzerinde çarpma deneyi yapılmıştır. Deney sonucunda plakta oluşan çökme değeri sınırlayıcı olarak seçilerek plaklar arasındaki şeklin geometrisinin optimizasyonu yapılmıştır. Yapılan optimizasyon hesaplamaları ANSYS LS-DYNA paket programına ait APDL programlama dilinde yazılmıştır.
\end{abstract}

Anahtar kelimeler: Kompozit plak, Sandviç plak, Şekil optimizasyonu, LS-DYNA, Çarpma yükü.

\section{Shape optimization of sandwich plates under impact load}

\begin{abstract}
The behavior of plaques under impact loading differs from that of static loads. As soon as the object is impacted and the object is removed from the object, the strain distribution in the plate changes. In our work we aimed to optimize the geometry of the core material geometry placed between two plate plates by adding these stress changes to the calculations. For this purpose, the impact test was carried out on a polypropylene sandwich plate with mechanical properties. As a result of the experiment, the geometry of the shape between the plates was optimized by choosing the value of the collapse occurring in the plate. The optimization calculations made are written in APDL programming language of ANSYS LS-DYNA package program.
\end{abstract}

Keywords: Composite plate, sandwich plate, shape optimization, LS-DYNA, impact load.

\section{Giriş}

Sandviç malzemeler gibi mukavemeti yüksek olan malzemeler, klasik malzemelere kıyasla sahip oldukları yüksek ses izolasyonu, enerji absorbe eğilimi, hafiflik, darbelere karşı dayanım ve "eğilme rijitliği/ağırlık" oranı gibi önemli avantajlarından dolayı birçok alanda kullanılmaktadır. Ayrıca günümüzde bu malzemeler, hafif, sağlam, korozyona dayanaklı ve yüksek sıcaklıklarda işlenebilme özellikleri sayesinde geniş bir kullanım alanına sahiptir [1].

Sandviç malzemeler, rijit bir alt ve üst tabaka arasına kalın ancak oldukça hafif çekirdek malzemesinin yerleştirilmesiyle üretilirler. Malzeme teknolojisindeki gelişmeler, sandviç malzemelerin de birçok sektörde gittikçe artan oranlarda kullanılmalarını sağlamıştır [2]. Sandviç malzemeler; havac1lik ve uzay sanayiinde, savunma sanayiinde, mermer sanayinde, ambalaj sanayiinde; denizcilikte, endüstriyel yapılarda, otomotiv sektöründe, yalıtım sistemlerinde, mobilyacılık sektöründe ve çoğu spor aletlerinde oldukça yaygın olarak kullanılmaktadır. İnşaat sektöründe ise bu malzemeler raylı ulaşım sistemlerinde, yapı mantolamalarında, duvar panellerinde, kapılarda, mimari dekorasyonlarda dekoratif profillerde, enerji absorbe edilebilen tampon tasarımlarında, viyadüklerde, virajı keskin olan yollarda kaza riskini azaltmak amacıyla kullanılan bariyerlerde yaygın kullanım alanlarına sahiptir. Mühendislik

*Sorumlu yazar: dbakir@firat.edu.tr

Geliş Tarihi: 08.01.2020, Kabul Tarihi: 27.11.2020 
yapılarında imalattan itibaren kullanım esnasında dışarıdan gelebilecek herhangi bir etkiye karşı istenmeyen sonuçların önüne geçmek için malzemenin bu tarz etkiler karşısında mekanik davranışının bilinmesi gerekir. Yapılacak darbe testleri ile malzemenin vereceği tepkiler görülebilir. Darbe testleri sonucu petek yapılı kompozitlerin, deformasyon, dayanım ve kırılma değerleri ile enerji absorbe özellikleri darbe yükleri altında elde edilebilir [3]. Çeşitli malzemeler, yapıştırıcılar ve farklı hücre boyutunun seçimi ile darbe direncinin optimumu elde edilebilir. Darbeyi yüzeye yayabilmek için daha kuvvetli bir yapıştırıcı ihtiyacı sandviç yapılarda birleştirmenin önemini göstermektedir [4]. Darbe testlerinde meydana gelen hasarların darbe alınan bölgenin etrafinda toplandığı, yüzeye yayılmadığı bilinmektedir [5]. Darbe ucu, panelin geometrisi, yapışma özelliği ve çekirdek yapısı darbe direncine bağlı özelliklerdir[6]. Bu çalışmada bir birine paralel ince levhalardan elde edilen sandviç panelin oluşturduğu çekirdek yapının deplasmanı, çelik bir kürenin $1 \mathrm{~m}$ yükseklikten yerçekimi ivmesi ile panelin üzerine düşürülmesi ile ölçülmüştür. Ölçülen deplasman değeri sınırlayıcı kabul edilerek farklı şekil ve kalınlıklar için optimum plak ağırlığı belirlenmiştir.

\section{Materyal ve Metot}

Deneyde çapları, $47.5 \mathrm{~mm}, 40.3 \mathrm{~mm}$ ve $30.7 \mathrm{~mm}$ olan üç farklı çelik küre ve Şekil 1'de görüleceği gibi sandviç plak olarak polipropilen malzeme içerikli çekirdeği ince yapılardan oluşan levha kullanıldı. Plak, $0.2 \mathrm{~mm}$ kalınlığında alt ve üst plaklardan fabrikasyon olarak imal edilen $200 \mathrm{~mm}$ x $200 \mathrm{~mm}$ kullanılmıştır. Çekirdek ise Şekil 2'de görüldüğü gibi kalınlığ $0.1 \mathrm{~mm}$ ve genişliği $2 \mathrm{~mm}$ olan birbirine paralel levhalar ve levhalar arası mesafe $4 \mathrm{~mm}$ geometrisine sahiptir. Malzemenin ve kürenin mekanik özellikleri ise Tablo 1'de verilmiştir.

Tablo 1. Plak ve çelik kürenin mekanik özellikleri

\begin{tabular}{lll}
\hline Elastisite Modülü (Plak) & Poisson Oranı (Plak) & Yoğunluğu (Plak) \\
\hline $152192 \mathrm{gr} / \mathrm{mm}^{2}$ & 0.34 & $0.00184 \mathrm{gr} / \mathrm{mm}^{3}$ \\
\hline Elastisite Modülü (Çelik & Poisson Oran1 & Yoğunluğu \\
Küre) & (Çelik Küre) & (Çelik Küre) \\
\hline $0.0078 \mathrm{gr} / \mathrm{mm}^{2}$ & 0.30 & $2.1 \times 10^{7} \mathrm{gr} / \mathrm{mm}^{3}$ \\
\hline
\end{tabular}

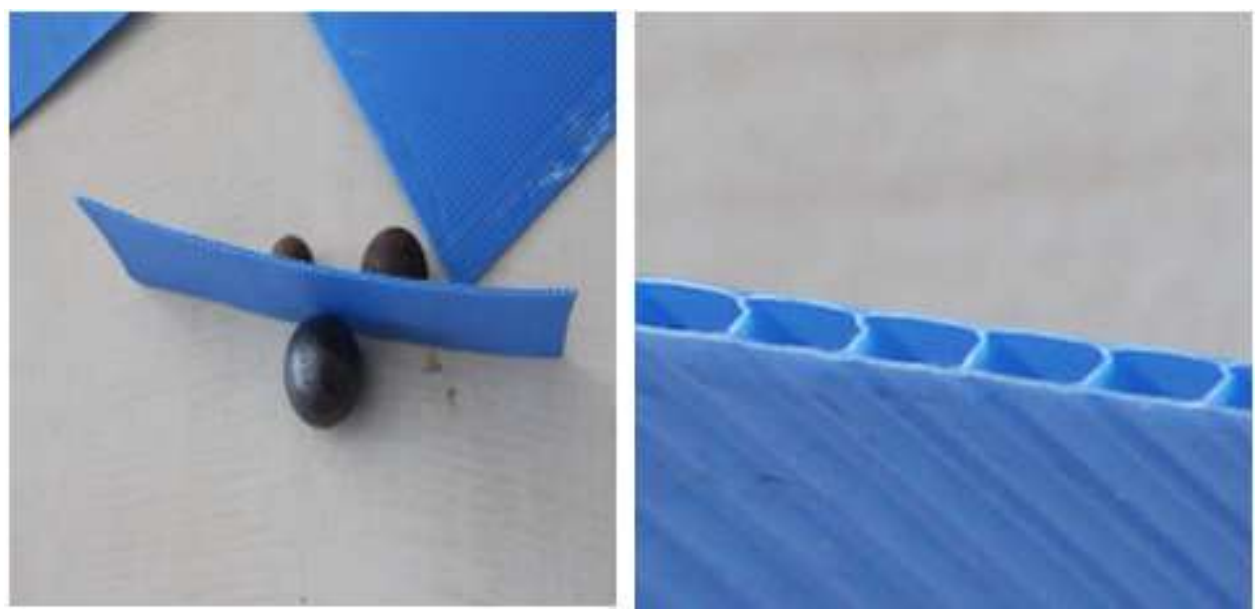

Şekil 1. Polipropilen levha kesiti ve çelik küreler

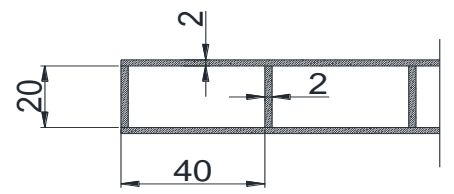

Şekil 2. Polipropilen sandviç levha en kesiti

Sandviç levha Şekil 3'de görüldüğü gibi iki ayrı ahşap çerçeve ile mesnetlemek için kayma mukavemeti $10 \mathrm{~kg} / \mathrm{mm}^{2}$ 'lik yapıştırıcı ile sabitlendi. 


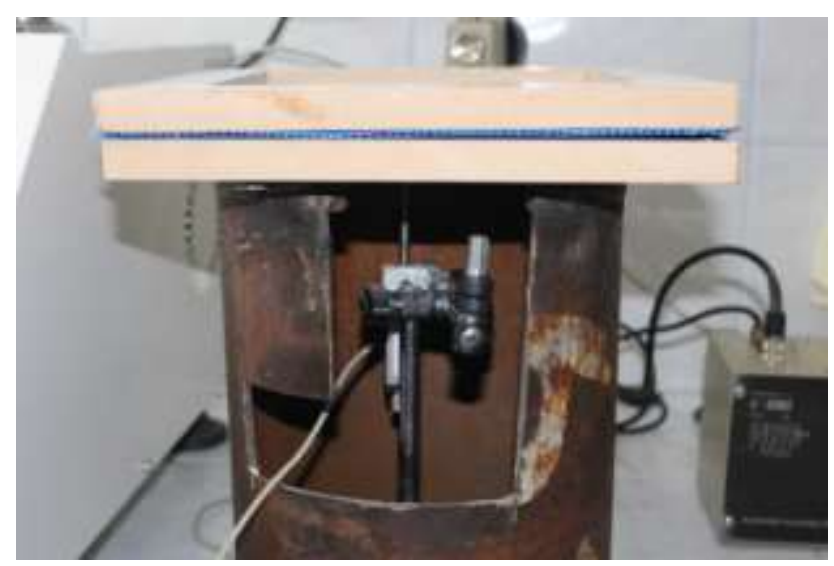

Şekil 3. Polipropilen sandviç levha en kesiti

Şekil 4'de görüldüğü gibi 1 m mesafeden 3 kürede düşürülerek sandviç plakta çarpma sonucu oluşan maksimum deplasman ölçüldü.

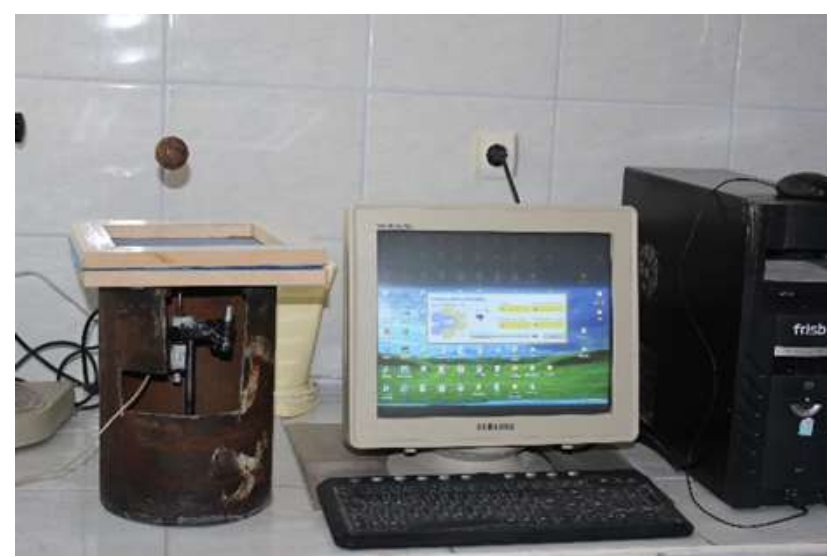

Şekil 4. Çarpma deneyi

Kürelerin darbe etkisi bilgisayar simülasyonuyla karşılaştırması yapılarak hesapların doğrulaması yapılmıştır. $1 \mathrm{~cm}$ ve $3 \mathrm{~cm}$ çaplarındaki kürelerin çarpması sonucunda levhada deplasman oluşmuştur. En büyük kürenin çarpmasından sonra plak yırtıldığı için şekil 5'de görüldüğü gibi deplasman ölçülememiştir.

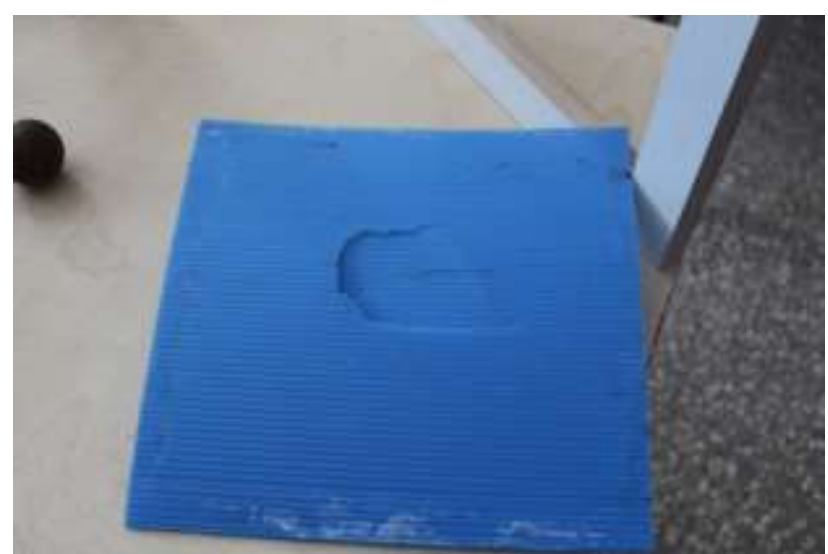

Şekil $5.4 \mathrm{~cm}$ çapındaki kürenin çarpması sonucu plakta oluşan yırtılma

3 cm'lik kürenin yaptığı çarpma darbesi sonucunda plakta $3 \mathrm{~mm}$ deplasman oluşmuştur. Yaptığımız optimizasyon hesaplamasında bu değer aşılmaması gereken sınır olarak belirlenmiştir. 


\subsection{Kesikli hareket denklemlerinin açık zaman entegrasyonu}

Bu çalışma, yerçekimi etkisi altında düşürülen çelik kürenin sandviç plakta oluşturduğu zamana bağlı deformasyon ve gerilmeleri belirleyerek plak hacmini optimize etmeyi amaçlamıştır. Bu zamana bağlı deformasyon denklemleri ile denge denklemleri birleştirilerek dinamik uygulama gerçekleştirilmiştir. $\mathrm{Bu}$ entegrasyon kapalı veya açık yöntemler kullanılarak yapılabilir. Kapalı yöntemlerde, dinamik denklemler zaman entegrasyon operatörü ile birleştirilir ve deplasmanlar doğrudan bulunur. Öte yandan, açık yöntemlerde, ivme, dinamik denklemlerden belirlenir ve sonra yer değiştirmelerin elde edilmesi için entegre edilir. Newmark'ın sabit hızlandırma yöntemi gibi en yaygın örtülü entegrasyon yöntemleri koşulsuz olarak kararlıdır [7]. Bu zaman adımlarının yalnızca yakınsamalı bir doğrulukla sınırlı olduğunu gösterir. Ancak, örtük yöntemler her zaman doğrusal olmayan bir dizi cebirsel denklem gerektirir. Ayrıca, örtülü entegrasyon için, hataları kontrol etmek ve farklılaşmayı önlemek için adımları tekrarlamak gereklidir. Bu nedenle, adım başına sayısal işlem sayısı her zaman açık entegrasyondan üç kat daha büyüktür [8]. Açık FEM analizi, yük (veya yer değiştirme) için aşamalı prosedürü uygular ve her bir artışın sonunda, geometrik ve malzeme değişikliklerine (varsa) dayanarak rijitlik matrisini günceller. Daha sonra, yeni bir rijitlik matrisi oluşturulur ve sisteme bir sonraki yük artışı (veya yer değiştirme) uygulanır. Bu metot, harici olarak uygulanan yüklerle içyapı kuvvetlerinin dengesini bozmaz.

Merkezi fark yöntemi gibi açık yöntemlerde, doğrusal olmayan davranışların oldukça belirgin bir çözümü vardır ve tekrarlamaya gerek yoktur. Her zaman adımında çözülecek olan ayrık hareket denklemleri sistemi aşağıdaki gibidir.

Dinamik denklem formül 1 de verildiği gibidir;

$$
M \ddot{U}+C \dot{U}+K U=F
$$

Burada, M yapının kütle matrisi, C sönümleme matrisi, K rijitlik matrisi, F dış kuvvet vektörü, nodal ivme vektörü, nodal hız vektörü, ve U yapının deplasman vektörüdür.

$0, t_{1}, t_{2}, \ldots, t_{n}$ zamanında yapının hızı ve ivmesi bilinirse, $t_{n+1}(t+\Delta t)$ anında yapının deplasmanı belirlenebilir. Merkezi fark, hız türevinin merkezi farkını değiştirmek için kullanılırsa;

$$
\dot{U}_{t}=\frac{1}{2 \Delta t}\left(-U_{t-\Delta t}+U_{t+\Delta t}\right)
$$

Denklem 1, denklem 2 ile yer değiştirilse aşağıdaki durum elde edilir.

$$
\begin{aligned}
& \widehat{M} U_{t+\Delta t}=\widehat{R}_{t} \\
& \widehat{M}=\frac{1}{\Delta_{t}^{2}} M+\frac{1}{2 \Delta_{t}} C \\
& \widehat{R_{t}}=F_{t}-\left(K-\frac{2}{{\Delta_{t}}^{2}} M\right) U_{t}-\left(\frac{1}{\Delta_{t}^{2}} M-\frac{1}{2 \Delta_{t}} C\right) U_{t-\Delta t}
\end{aligned}
$$

Burada, $\widehat{R_{t}}$ yük vektörü, $\widehat{M}$ etkili kütle matrisi, $F_{t}$ yapısal yük vektörüdür.

(4) nolu lineer denklem $t+\Delta t$ zamanındaki $U_{(t+\Delta t)}$ deplasman vektörünü verir. $U_{(t+\Delta t)}$,

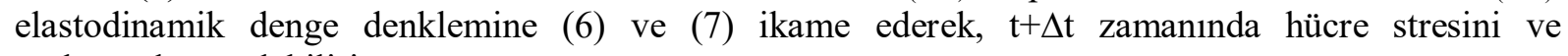
zorlanmaların alabiliriz.

Geometrik denklemler:

$$
\varepsilon_{i j}=\frac{1}{2}\left(u_{i j}+u_{j i}\right)
$$


Fiziksel denklemler:

$$
\begin{aligned}
& \delta_{i j}=\lambda \varepsilon_{k k} \delta_{i j}+2 \mu \varepsilon_{i j} \\
& \sigma_{k k}=(3 \lambda+2 \mu) \varepsilon_{k k}=3 K \varepsilon_{k k}
\end{aligned}
$$

Karş1lıklı çözüme göre, denklemlerin merkezi fark yöntemi ile çözümü, hesaplama kapanış koşulları altında gerçekleşene kadar devam eder [9]. Merkezi fark yöntemi açık bir algoritmadır ve stabildir. Başka bir deyişle problemleri çözmek için bu yöntemi kullanırken, zaman adımlarının büyüklüğü problem çözüm denkleminin işleyişi tarafından belirlenen bir adımın altında olmalıdır[10].

\subsection{Modelleme ve optimizasyon algoritmsının uygulanması}

Optimizasyon, birçok bilim ve mühendislik alanında önemli bir araçtır. Birçok modelleme, tasarım, kontrol ve karar verme problemleri matematiksel optimizasyona dayanarak formüle edilebilir. Başka bir deyişle en iyi olarak kastedilen kriteri hedef olarak belirleyip, matemetiksel fonksiyonla temsil ettirilip, belirtilen sınırlar ölçüsünde fonksiyonun minimum bazen de maksimum değerinin bulunmasıdır [11]. Optimizasyonun diğer bir amacı, yapıyı tam gerilmeye zorlamaktır. Tam gerilmeye zorlanma sonucu yap1 optimum şeklini belirler. Mühendislik problemlerinin çoğu, genellikle sınırlayıcılı minimizasyonu içerir. Sınırlandırılmış bir yapının minimum ağılık tasarımının, gerilme ve deplasman üzerinde bulunması, bu tür kısıtlı minimizasyon probleminin bir örneğidir. Optimum ağırlık-mukavemet oranı elde etmek amaciyla kullanılan optimizasyon metotları, seviye ayar metodu, malzeme bulut metodu, genetik algoritma, evrimsel metot ve eleman silme metodu gibi metotlar kullanılarak uygulanmaktadır[12].

Optimum bir tasarım için çalışırken, tasarım sürecini karakterize eden üç tip değişken vardır; tasarım değişkenleri, durum değişkenleri ve amaç fonksiyonu. Bu değişkenler, APDL'de (ANSYS Paremetric Design Language) skaler parametrelerle temsil edilir. APDL'de bağımsız değişkenler tasarım değişkenleridir. Tasarım değişkeni kısıtlamaları, yan sınırlar olarak adlandırılır ve genel olarak uygulanabilir tasarım alanı olarak tanımlanır.

$$
\begin{array}{lll}
\text { Minimize } & f=f(x) & \\
\text { sinırlayıc1lar } & g_{i}(x) \leq g i & i=1, \ldots \ldots . ., m_{1} \\
& \underline{h}_{i} \leq h_{j}(x) 0 & i=1, \ldots \ldots . ., m_{2} \\
& \underline{w}_{i} \leq w i(x) \leq w_{i} & i=1, \ldots \ldots ., m_{3}
\end{array}
$$

Burada: $\quad f \quad=$ amaç fonksiyonu

$g_{i}, h_{i}, w_{i}=$ durum değişkenleri

$\mathrm{m}_{1}, \mathrm{~m}_{2}, \mathrm{~m}_{3}=$ durum değişkeni sayıs

ANSYS paket programında sayısız optimizasyon yöntemi kullanılmıştır (first-order, subproblem approximation, random design generation, the sweep tool, gradient evaluation tool). $\mathrm{Bu}$ çalışmada, optimizasyon algoritması olarak birinci dereceden optimizasyon yöntemi (first-order) kullanılmıştır.

Birinci mertebeden yöntemde, amaç fonksiyona ceza fonksiyonları ekleyerek soruyu sınırsız bir hale dönüştürür. Birinci mertebeden yöntem, tasarım değişkenlerine göre bağımlı değişkenlerin gradyanlarını kullanır. Her bir iterasyon için, bir arama yönünü belirlemek amacıyla gradyan hesaplamaları (en dik iniş ya da eşlenik yön metodu kullanılarak) gerçekleştirilir ve kısıtlanmamış problemi en aza indirmek için bir çizgi arama stratejisi benimsenir. Böylece, her yineleme, arama yönünü ve gradient hesaplamaları içeren birkaç alt yinelemeden oluşur. Bu nedenle, bir optimizasyon yinelemesi first order yöntemi için birkaç analiz döngüsü gerçekleştirir [13].

Kısıtsız bir problem aşağıdaki gibi formüle edilir. 


$$
Q(x, q)=\frac{f}{f_{0}}+\sum_{i=1}^{n} P_{x}\left(x_{i}\right)+q\left\{\sum_{i=1}^{m_{1}} P_{g}\left(g_{i}\right)+\sum_{i=1}^{m_{2}} P_{h}\left(h_{i}\right)+\sum_{i=1}^{m_{3}} P_{w}\left(w_{i}\right)\right\}
$$

Burada;

$\mathrm{Q}$ : boyutsuz ve sınırlandırıcısı olmayan amaç fonksiyonu

$\mathrm{Px}, \mathrm{Pg}, \mathrm{Ph}$, ve Pw: kısıtlı tasarıma ve durum değişkenlerine uygulanan cezalar,

Kisıtların uygunluğu q, yanıt yüzeyi parametreleri tarafindan kontrol edilir.

Harici ceza fonksiyonu (Px) tasarım değişkenlerine uygulanır. Durum değişken kısıtlamaları genişletilmiş iç ceza fonksiyonları $(\mathrm{Pg}, \mathrm{Ph}, \mathrm{Pw})$ ile ifade edilir.

$$
\begin{aligned}
& Q_{f}(x)=\frac{f}{f_{0}} \\
& Q_{p}(x, q)=\sum_{i=1}^{n} P_{x}\left(x_{i}\right)+q\left\{\sum_{i=1}^{m_{1}} P_{g}\left(g_{i}\right)+\sum_{i=1}^{m_{2}} P_{h}\left(h_{i}\right)+\sum_{i=1}^{m_{3}} P_{w}\left(w_{i}\right)\right\}
\end{aligned}
$$

Sonra denklem (8) aşağıdaki formu alır,

$$
Q(x, q)=Q_{f}(x)+Q_{p}(x, q)
$$

Qf ve Qp fonksiyonları sırasıyla amaç fonksiyonu ve ceza kısıtlayıcılarıyla ilişkilidir.

\subsection{Uygulanan algoritma}

Programın algoritması Şekil 6'da verilen akış diyagramına göre yapılarak simülasyon programı hazırlanmıștır. Hazırlanan simülasyon programı aşağıdaki adımlarla gerçekleştirildi.

- Üç tip çekirdek yapısına göre modelleme yapıldı.

- Plak elemanlarını toplamının hacmi hesaplandı.

- Küre modellemesi yapıldı ve 1 m yükseklikten kürenin plağa çarpma anındaki hızı hesaplanarak çelik küre plağa yakın konuma getirildi.

- Çarpma anının başlangıcından plakta çarpmadan dolayı oluşan titreşimlerin sönümlendiği zamana kadarki maksimum plak ortası deplasman hafizaya alındı.

- Optimizasyon için plak üst ve alt tabakalarına ait kalınlıklar, çekirdek geometrisi ve plak ortası deplasmanı sınırlayıcı olarak tanımlandı. Amaç fonksiyonu ise sandiviç plak toplam hacmi alındı.

- First order metodu uygulanarak minimum hacim elde edilene kadar döngü devam etti.

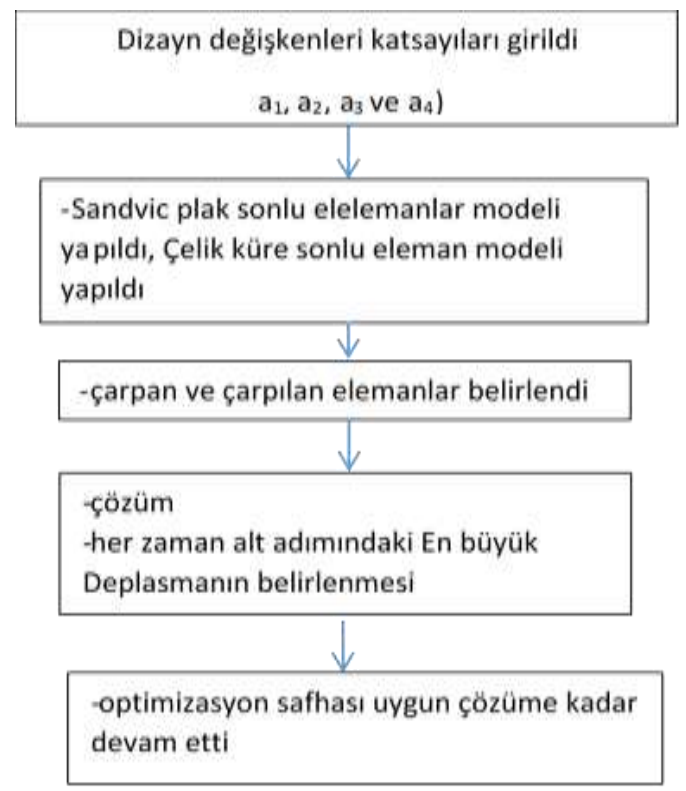

Şekil 6. Optimizasyon veri akış diyagramı 


\subsection{Deneyin similasyonu ve optimum çekirdek şeklinin elde edilmesi}

Laboratuvar şartlarında yaptığımız deneyde sadece çekirdeği birbirine paralel levhalardan oluşan sandviç panel kullanılmıştır. Aşağıdaki Şekil 7 ve 8 'de görüldüğü gibi hem deneyinin ve hem de simülasyonu yapılan sandviç panel görülmektedir. 200x200 mm boyutlarında olan bu plak dört kenarından X, Y, Z yönünde deplasman yapması önlenmiştir. Sonraki analiz safhasında üç farklı şekle sahip çekirdekli levha üzerinde yapılmıştır. Optimizasyon kısmı bu şekillere uygulanarak en ekonomik şekil belirlenmiştir. Çözüm için deneyde kullanılan sandviç plağın boyutları ve değişkenleri Şekil 7 ve Tablo 2'de verilmiştir.



Şekil 7. Sandviç plağın geometrik değişkenleri

Tablo 2. Sandiviç Plağın boyutları

\begin{tabular}{ccccc}
\hline $\mathrm{a} 1$ & $\mathrm{a} 2$ & $\mathrm{a} 3$ & $\mathrm{a} 4$ & Hacim \\
\hline $4.00 \mathrm{~mm}$ & $0.20 \mathrm{~mm}$ & $0.20 \mathrm{~mm}$ & $2.00 \mathrm{~mm}$ & $24000 \mathrm{~mm}^{3}$
\end{tabular}

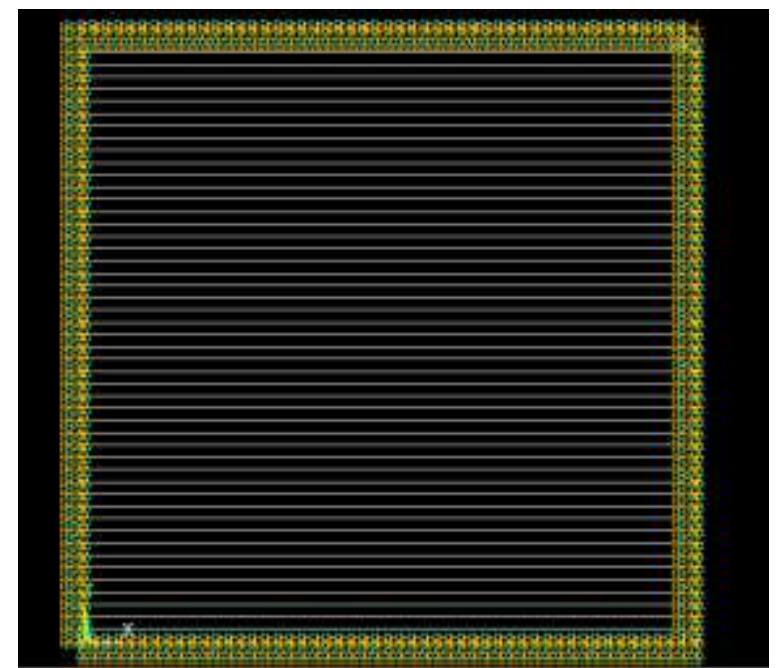

Şekil 8. Birbirine paralel dikdörtgen çekirdekli sandviç panel

\subsection{Deney Sonuçları ile Simülasyonun ile Karşılaştırılması}

Simülasyon, yapılan deney şartlarına birebir uygunluğu 3 küre içinde yapıldı (Şekil 9). Yapılan deneyde küre $1 \mathrm{~m}$ 'den düşürülmesine rağmen bu mesafe analiz süresini uzatacağ 1 için hesaplamada çarpan küre çarpılan levhaya $2 \mathrm{~mm}$ mesafeye getirildi. Buna karşılık kürenin başlangıç hızı yerçekimi ivmesi göz önünde bulundurularak $4.5 \mathrm{~m} / \mathrm{sn}$ olarak alındı. Çarpma süresinin ayarlanmasında kürenin plağa temasının başlaması ve teması kestikten sonra plaktaki titreşimlerin bitme anına kadar geçen süre $3 \mathrm{sn}$ alınmıştır. Bu 3 sn'lik süre 50 Kısıma bölünerek 150 defada sistemde meydana gelen deplasman ve gerilmeler hafizaya kaydedilmiştir. Bu değerlerin maksimumu hafizaya alınarak yapılan deneyle karşılaştırma yapılarak modellemenin doğruluğu belirlenmiştir. Aşağıda simülasyonun çeşitli anlarındaki gerilme dağılımları ve deformasyonlu şekiller görülmektedir. İlk şekil değiştirme 7 . Zaman aralığında olmuştur (Şekil 10). Sonra büyük fark görünen zaman aralıklarındaki şekiller verilmiştir (Şekil 11-18). 


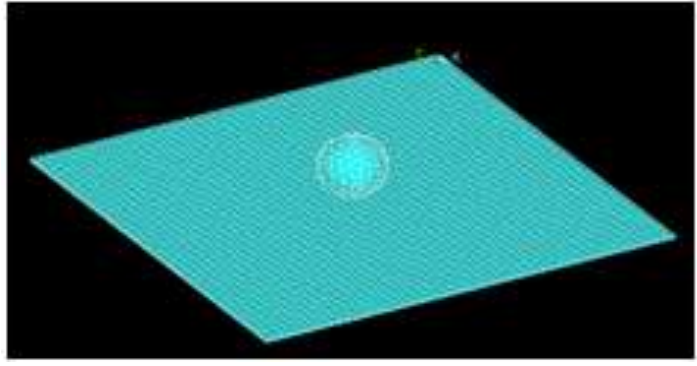

Şekil 9. Simülasyon başlangıcında cisimlerin konumu

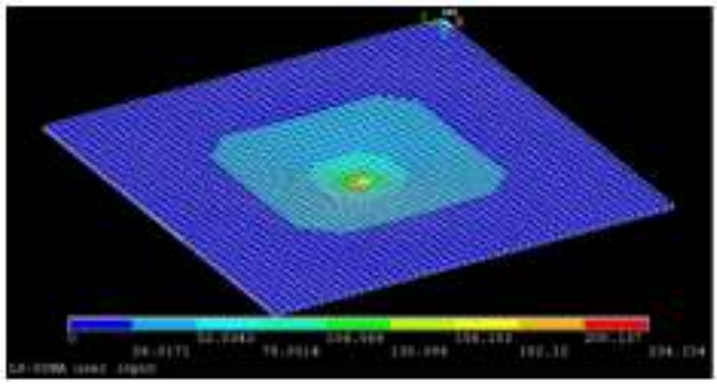

Şekil 11. 8. adım (8. Step)

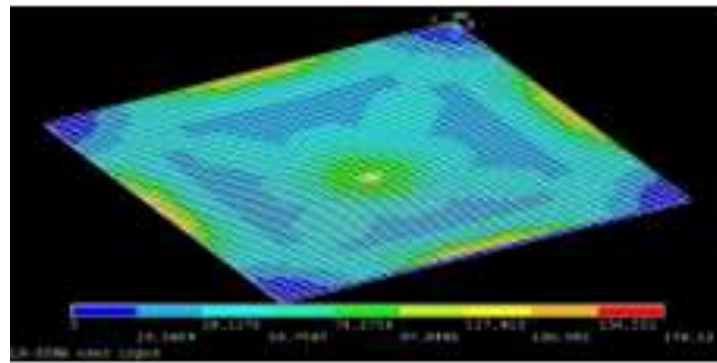

Şekil 13. 10. Adım (10.step)

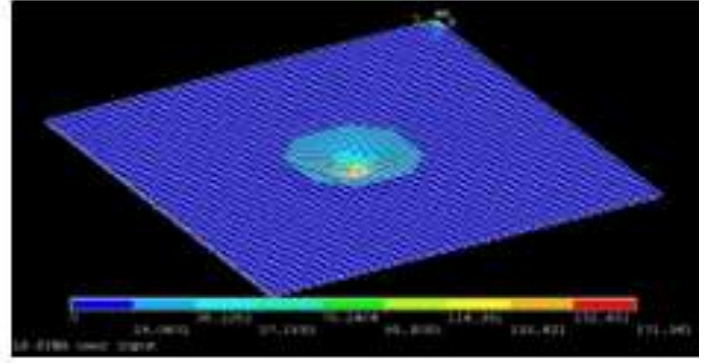

Şekil 10. 7. zaman adımındaki adım

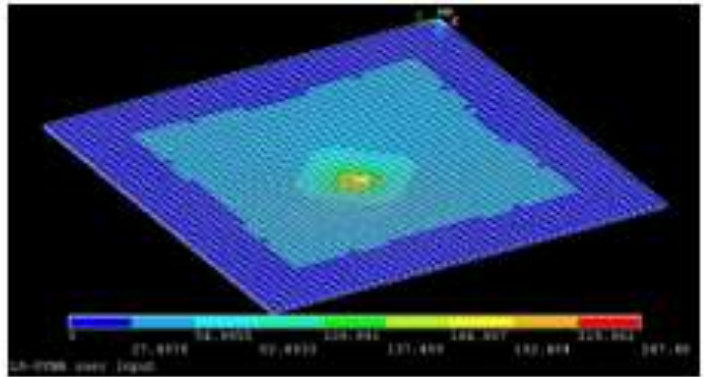

Şekil 12. 9. Adım (9.step)

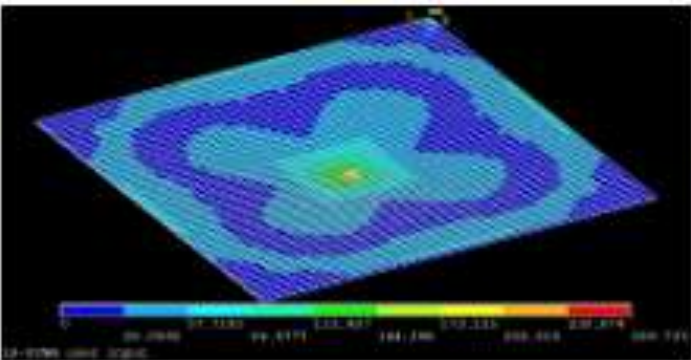

Şekil 14. 11. Adım (11.step)

$\mathrm{Bu}$ deney sonucunda elde ettiğimiz dataları daha ekonomik bir şekil elde etmek için önce deneydeki malzemenin simülasyonu yapan programa optimizasyon kodları yazarak aynı çarpma yük altında daha ekonomik sonucu elde edecek programı yazarak aşağıda yapılan modelleme ve çarpma sonucunda oluşan zamana göre gerilme dağılım gösteren şekiller sunulmuştur. 35. zaman aralığından sonra plak yukarı doğru tersyönde hareket etmeye başlamıştır (Şekil 19-20). Bu aralıkta kürenin teması kesilmiş olup çarpma işlemi bitmiş ancak gerilme değişimleri devam etmektedir (Şekil 21).

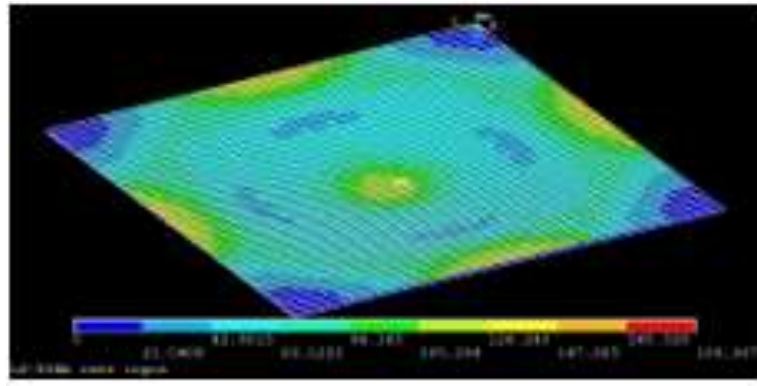

Şekil 15. 12. Adım (12.step)

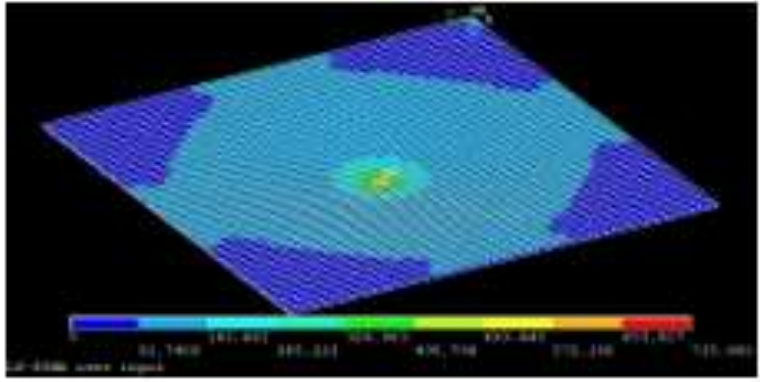

Şekil 16. 15. Adım (15.step) 


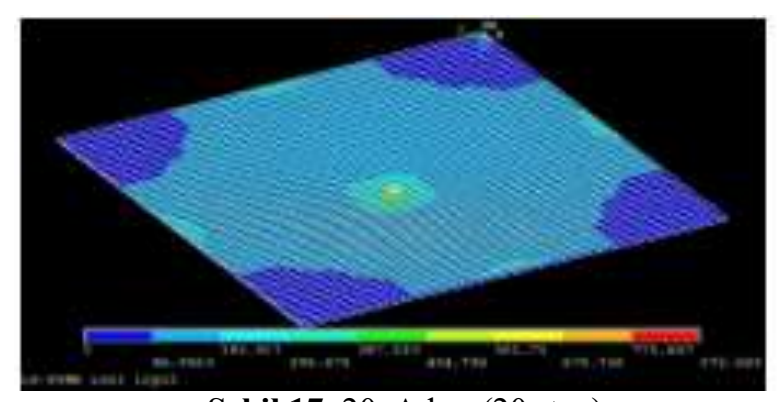

Şekil 17. 20. Adım (20.step)

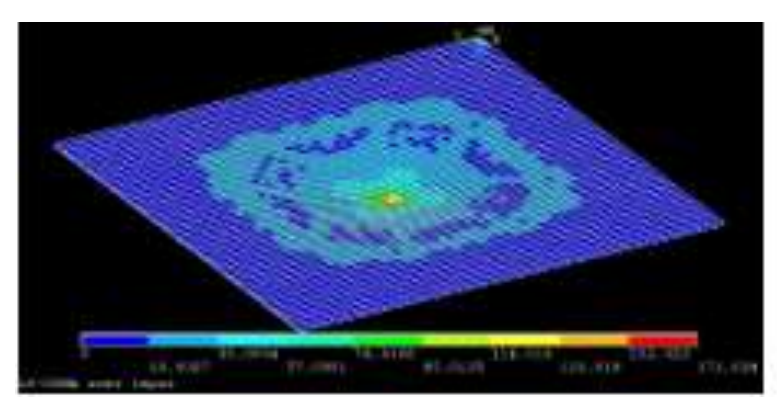

Şekil 19. 35. Adım (35.step)

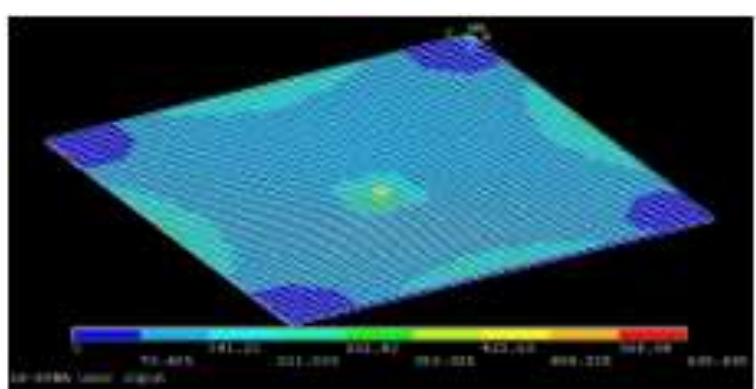

Şekil 18. 25. Adım (25.step)

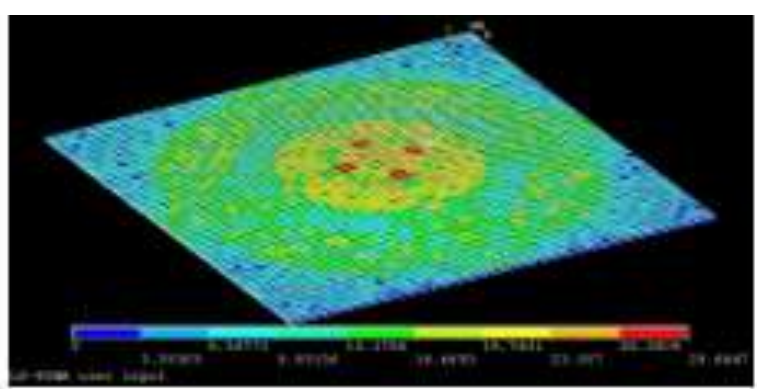

Şekil 20. 40. Adım (40.step)

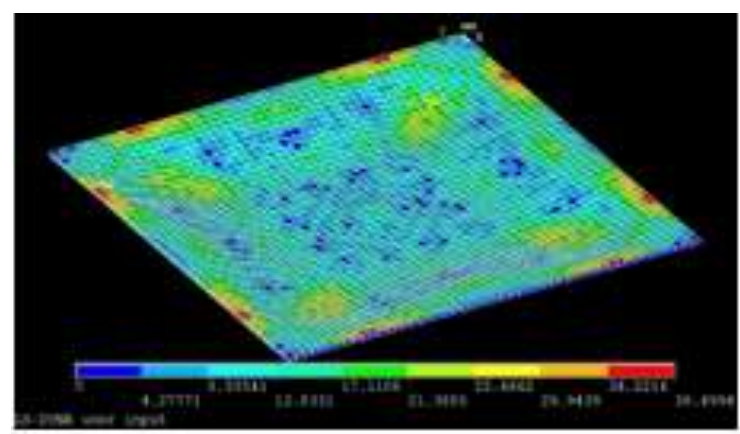

Şekil 21. 45. Adım (45.step)

\subsection{Optimizasyon sonucunda ekonomik şeklin belirlenmesi}

Optimizasyon probleminde levhanın toplam hacmini minimize etmek için amaç fonksiyonu levha hacmi alınmıştır. Sınırlayıcılar ise deney sonucunda elde edilen maksimum deplasman sınırlayıcısı, levhanın alt ve üst plaklarının kalınlığı, çekirdek kısmı oluşturan plaklar arasındaki mesafe, bu plakların yüksekliği ve kalınlığı sınırlayıcı olarak alınmıştır. Problemde kullanılan üç farklı çekirdek tipi şekil 8, 22, 23 te görülmektedir. Çekirdekleri oluşturan başlangıç nodlama dizilimi üç problemde de aynı olup başlangıç nod koordinatları aynıdır. Optimizasyon safhasında verilen sınırlayıcıların alt ve üst sınır değerleri;

$1,00 \mathrm{~mm}<$ deplasman $<3.00 \mathrm{~mm}$

$3,10 \mathrm{~mm}<\mathrm{a} 1<5,10 \mathrm{~mm}$,

$0,01 \mathrm{~mm}<\mathrm{a} 2<0,50 \mathrm{~mm}$,

$0,01 \mathrm{~mm}<\mathrm{a} 3<0,50 \mathrm{~mm}$,

$1,10 \mathrm{~mm}<\mathrm{a} 4<4,90 \mathrm{~mm}$ ' dir.

Toplam hacim birinci modelde $20,080.00 \mathrm{~mm} 3$, ikinci modelde $24,000.00 \mathrm{~mm} 3$ ve üçüncü altıgen geometriye sahip çekirdek modelinin hacmi 24,000.00 $\mathrm{mm} 3$ tür. Yapılan optimizasyon iterasyon sayıs1 sirasıyla, 7,17 ve 11 'dir. 


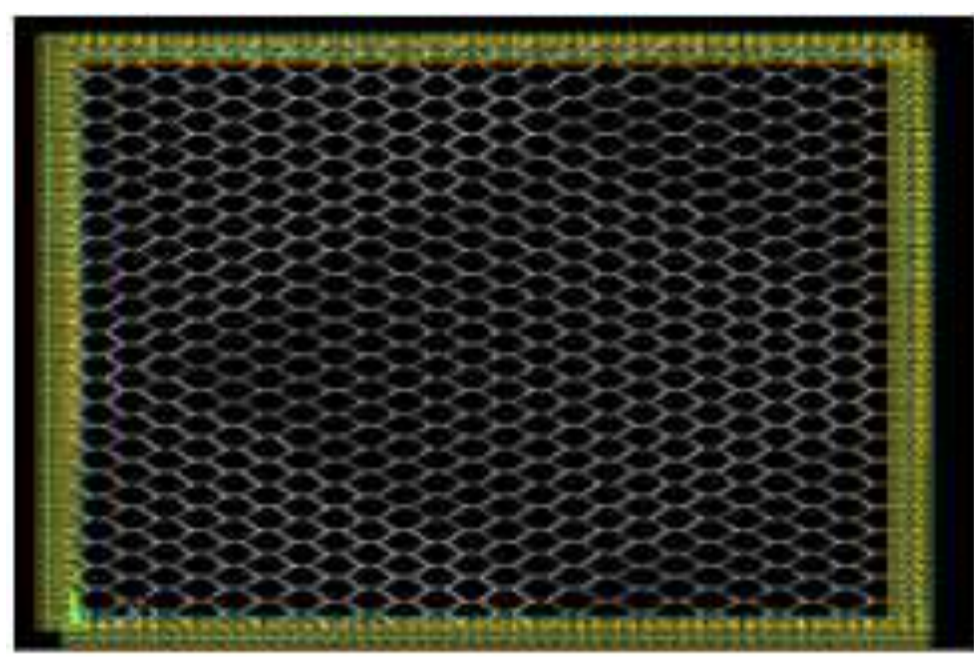

Şekil 22. Birbirini kesen dikdörtgen çekirdekli sandviç panel

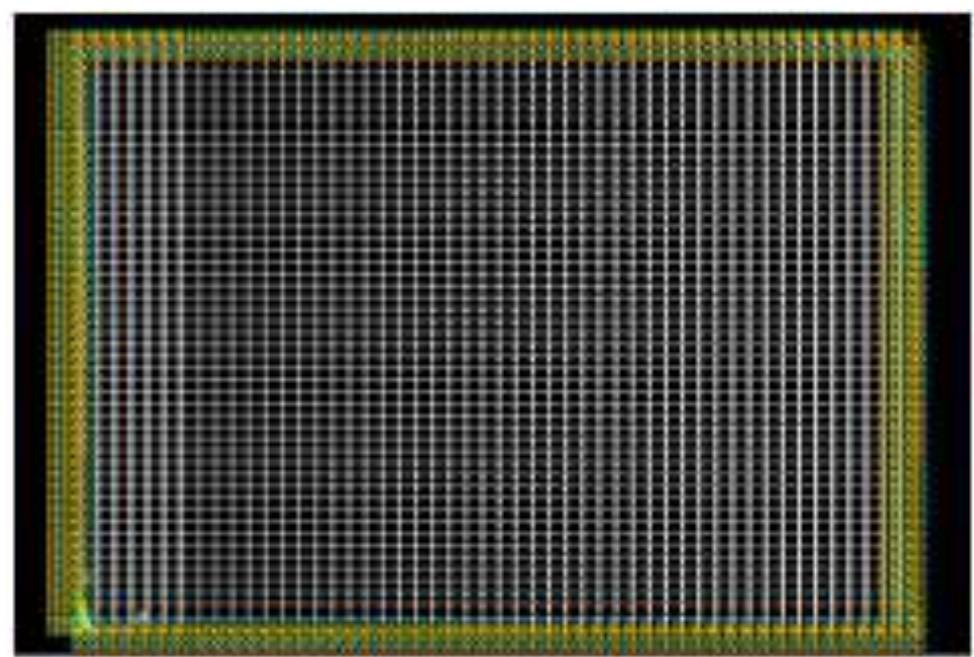

Şekil 23. Altıgen çekirdekli sandviç panel

\section{Bulgular ve Tartışma}

Optimizasyon sonrası her hesap adımına göre değişkenlerin ve toplam hacmin değerleri aşağıdaki Tablo 2,3 ve 4 'te verilmiştir. Paralel dikdörtgen levha şeklindeki çekirdek şeklinde olan plakta toplam hacmi $13,023.05 \mathrm{~mm}^{3}$, bir birini kesen dikdörtgen levha şekilli çekirdekte toplam hacim $11,848.68 \mathrm{~mm}^{3}$ ve altıgen şekilli çekirdeğe sahip sandviç panelin toplam hacmi ise $10,630.13 \mathrm{~mm}^{3}$ 'e inmiştir.

Tablo 3. Paralel levhalı çekirdek

\begin{tabular}{crrrrrr}
\hline $\begin{array}{c}\text { Döngü } \\
\text { No }\end{array}$ & $\begin{array}{c}\text { Deplasman } \\
(\mathrm{mm})\end{array}$ & $\begin{array}{c}\mathrm{a} 1 \\
(\mathrm{~mm})\end{array}$ & $\begin{array}{c}\mathrm{a} 1 \\
(\mathrm{~mm})\end{array}$ & $\begin{array}{c}\mathrm{a} 1 \\
(\mathrm{~mm})\end{array}$ & $\begin{array}{c}\mathrm{a} 1 \\
(\mathrm{~mm})\end{array}$ & $\begin{array}{c}\text { Hacim } \\
\left(\mathrm{mm}^{3}\right)\end{array}$ \\
\hline 1 & 2,440061 & 4,000000 & 0,200000 & 0,200000 & 2,000000 & 20080.00 \\
2 & 2,925030 & 4,000000 & 0,139903 & 0,184675 & 1,907834 & 14785.97 \\
3 & 2,913922 & 3,998965 & 0,138628 & 0,184292 & 1,905670 & 14672.51 \\
4 & 2,934868 & 3,998033 & 0,138229 & 0,184198 & 1,905130 & 14637.72 \\
5 & 2,983362 & 3,967828 & 0,131083 & 0,182079 & 1,894201 & 14004.57 \\
6 & 3,008791 & 3,957932 & 0,124392 & 0,172552 & 1,900298 & 13295.94 \\
7 & 3,042558 & 3,947040 & 0,121797 & 0,168913 & 1,903345 & 13023.05 \\
\hline
\end{tabular}


Tablo 4. Kesişen levhalı çekirdek

\begin{tabular}{|c|c|c|c|c|c|c|}
\hline Döngü No & $\begin{array}{c}\text { Deplasman } \\
(\mathrm{mm})\end{array}$ & $\begin{array}{c}\mathrm{a} 1 \\
(\mathrm{~mm})\end{array}$ & $\begin{array}{c}\mathrm{a} 2 \\
(\mathrm{~mm})\end{array}$ & $\begin{array}{c}\mathrm{a} 3 \\
(\mathrm{~mm})\end{array}$ & $\begin{array}{c}\mathrm{a} 4 \\
(\mathrm{~mm})\end{array}$ & $\begin{array}{l}\text { Hacim } \\
\left(\mathrm{mm}^{3}\right)\end{array}$ \\
\hline$\overline{1}$ & 2,440061 & 4,000000 & 0,200000 & 0,200000 & 2,000000 & 24160.00 \\
\hline 2 & 2,914534 & 4,000000 & 0,151590 & 0,175311 & 1,851517 & 18748.90 \\
\hline 3 & 2,891556 & 3,997015 & 0,149722 & 0,174301 & 1,846084 & 18541.93 \\
\hline 4 & 2,929814 & 3,995846 & 0,147975 & 0,173419 & 1,841365 & 18352.32 \\
\hline 5 & 2,975424 & 3,994908 & 0,145038 & 0,172219 & 1,826603 & 18020.42 \\
\hline 6 & 2,988531 & 3,993059 & 0,143352 & 0,170858 & 1,817044 & 17801.46 \\
\hline 7 & 2,998638 & 3,942392 & 0,138766 & 0,165877 & 1,792599 & 17167.21 \\
\hline 8 & 3,049480 & 3,921418 & 0,137516 & 0,164979 & 1,768745 & 16954.08 \\
\hline 9 & 3,068703 & 3,920480 & 0,137478 & 0,164936 & 1,768302 & 16948.06 \\
\hline 10 & 3,050190 & 3,920385 & 0,137481 & 0,164935 & 1,768179 & 16947.82 \\
\hline 11 & 2,852022 & 3,764482 & 0,134348 & 0,167249 & 1,877372 & 17153.21 \\
\hline 12 & 3,015786 & 3,764214 & 0,120447 & 0,160581 & 1,841776 & 15669.17 \\
\hline 13 & 3,024252 & 3,763879 & 0,119794 & 0,160160 & 1,842488 & 15603.38 \\
\hline 14 & 3,061283 & 3,100000 & 0,119314 & 0,088953 & 1,526118 & 12314.50 \\
\hline 15 & 3,002627 & 3,101547 & 0,118451 & 0,087914 & 1,525138 & 12211.32 \\
\hline 16 & 3,001723 & 3,101547 & 0,114966 & 0,089334 & 1,535295 & 11995.20 \\
\hline 17 & 3,017010 & 3,101547 & 0,113669 & 0,088108 & 1,532864 & 11848.68 \\
\hline \multicolumn{7}{|c|}{ Tablo 5. Altıgen çekirdek } \\
\hline Döngü No & $\begin{array}{c}\text { Deplasman } \\
(\mathrm{mm})\end{array}$ & $\begin{array}{c}\mathrm{a} 1 \\
(\mathrm{~mm})\end{array}$ & $\begin{array}{c}\mathrm{a} 2 \\
(\mathrm{~mm})\end{array}$ & $\begin{array}{c}\mathrm{a} 3 \\
(\mathrm{~mm})\end{array}$ & $\begin{array}{c}\mathrm{a} 4 \\
(\mathrm{~mm})\end{array}$ & $\begin{array}{l}\text { Hacim } \\
\left(\mathrm{mm}^{3}\right)\end{array}$ \\
\hline 1 & 2,593171 & 4,000000 & 0,200000 & 0,200000 & 2,000000 & 24160.00 \\
\hline 2 & 2,835099 & 4,000000 & 0,170983 & 0,185202 & 1,911000 & 20898.64 \\
\hline 3 & 2,942958 & 3,995550 & 0,162012 & 0,180748 & 1,885696 & 19914.03 \\
\hline 4 & 3,016450 & 3,442070 & 0,114897 & 0,164048 & 1,895377 & 15534.82 \\
\hline 5 & 2,722764 & 3,100000 & 0,106758 & 0,163699 & 2,049982 & 15386.52 \\
\hline 6 & 2,925307 & 3,100001 & 0,084567 & 0,152099 & 1,994271 & 12953.25 \\
\hline 7 & 2,990352 & 3,100001 & 0,080422 & 0,149606 & 1,985354 & 12492.96 \\
\hline 8 & 3,031577 & 3,100001 & 0,078536 & 0,148493 & 1,979321 & 12278.80 \\
\hline 9 & 3,032808 & 3,100001 & 0,078154 & 0,148224 & 1,977735 & 12232.53 \\
\hline 10 & 3,043525 & 3,100001 & 0,078197 & 0,147172 & 1,974354 & 12183.37 \\
\hline 11 & 2,869269 & 3,100001 & 0,111124 & 0,042382 & 2,012789 & 10630.13 \\
\hline
\end{tabular}

Her çekirdek şekli için optimizasyon adımına göre hacim değişimleri ise;

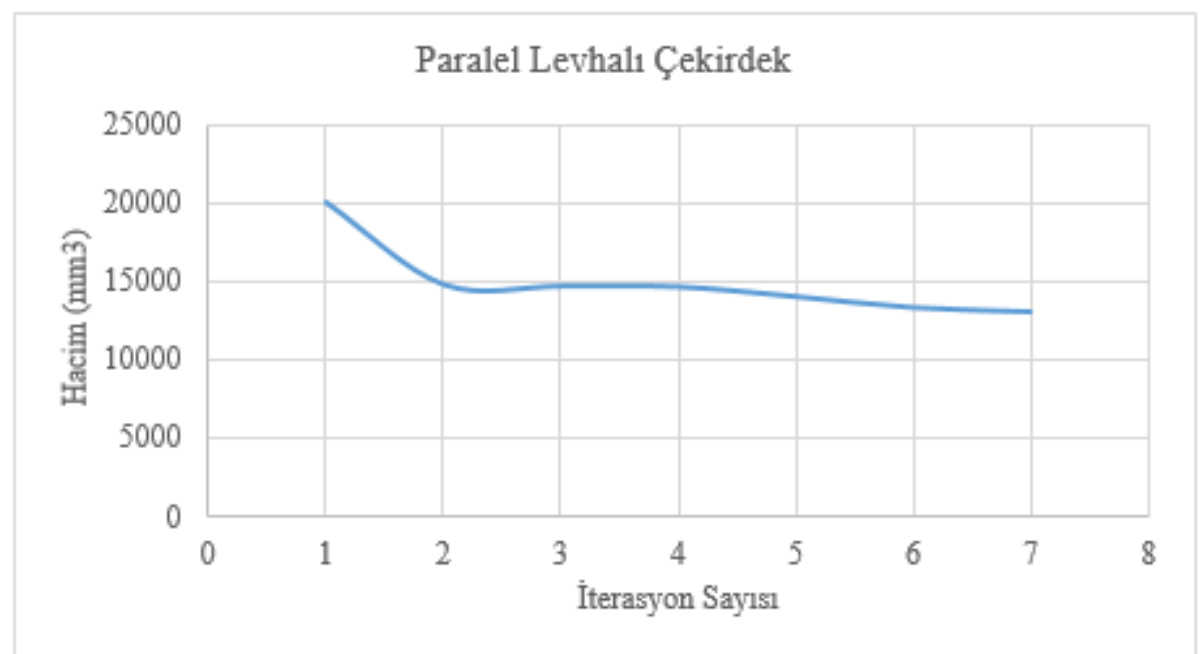

Şekil 24. Birbirine paralel dikdörtgen çekirdekli sandviç panelin hacim-döngü sayısı grafiği 


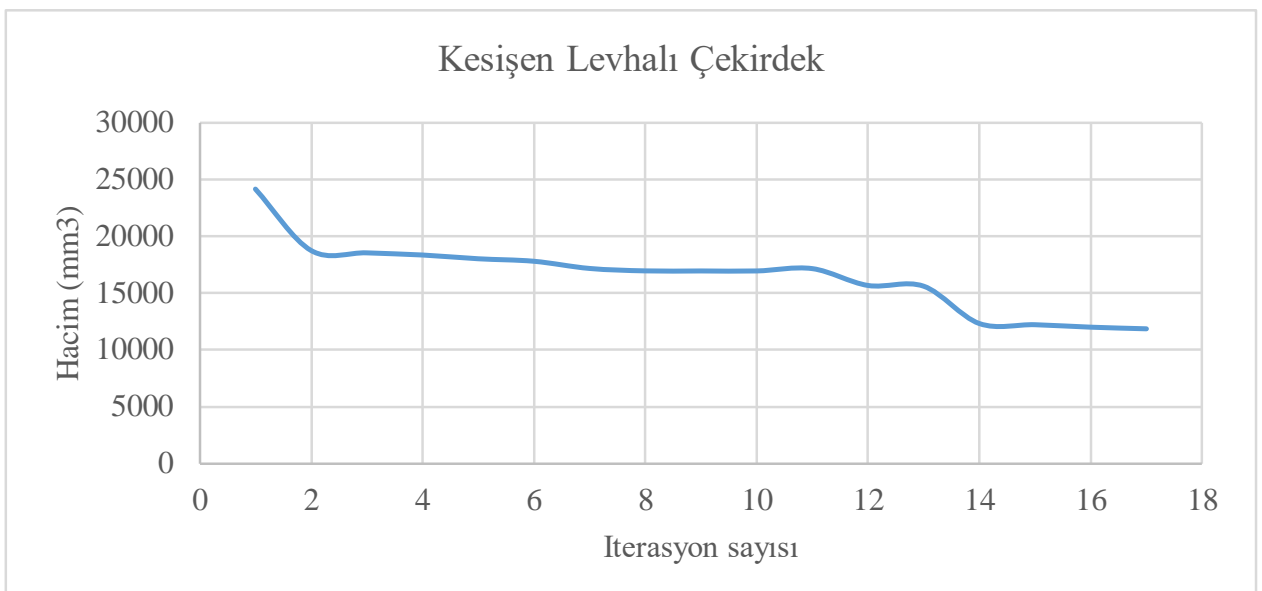

Şekil 25. Birbirini kesen dikdörtgen çekirdekli sandviç panelin hacim-döngü sayısı grafiği

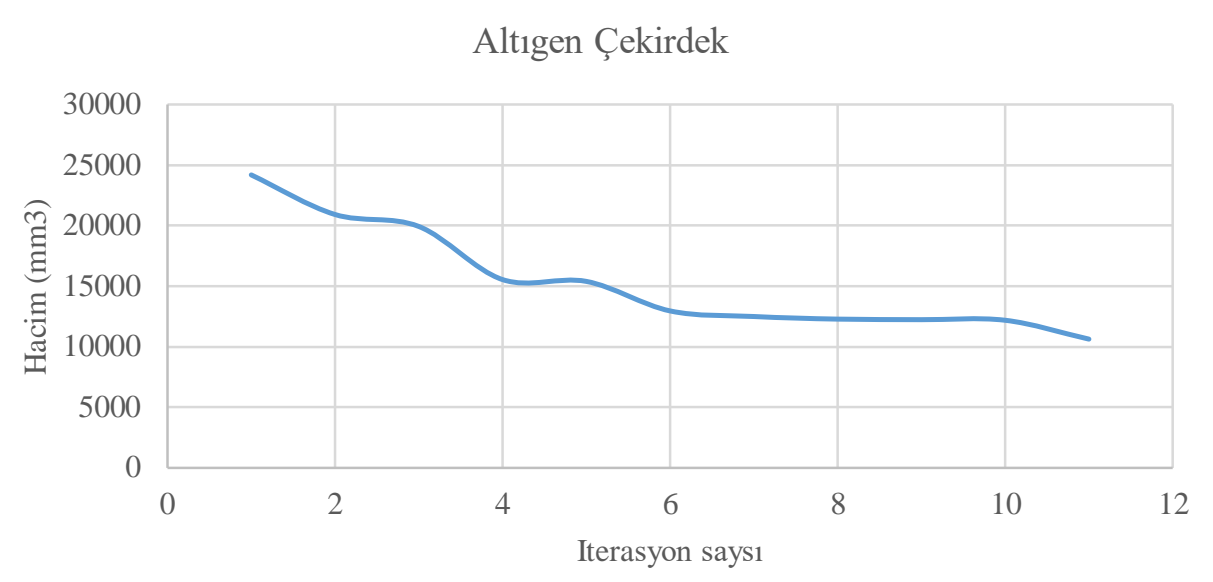

Şekil 26. Çekirdek şekli altıgen geometriye sahip sandviç panelin hacim-döngü sayısı grafiği

\section{Sonuç ve Öneriler}

Yapılan çalışma sandviç plakların optimum hacminin belirlenmesi için iki kısımdan oluşmuştur. İlk kısımda mekanik ve geometrik özellikleri bilinen bir sandviç plağa çarpma testi yapılmıştır. Deney sonucunda elde edilen plağın maksimum deplasmanı maksimum deplasman sınırı olarak belirlenmiştir. İkinci aşamada ise deney modellernerek bilgisayar simülasyonu yapılmış ve yapılan deney ile simülasyonun doğrulaması yapılmıştır. Sonra bu simülasyon üç farklı çekirdek şekli için uygulanarak optimizasyon algoritması ile optimize edilmiştir.

Yukardaki tablo ve grafiklerden de görüleceği gibi çarpma etkisi altında, altıgen şekle sahip çekirdekli sandviç plak en ekonomik bulunmuştur. Ancak fabrikasyon olarak üretim kolaylığ dikkate alındığında 1 no'lu çekirdek şeklinin optimizasyon sonucu hacminde ki azalma \%35 olmuştur. Buda fabrikasyon imalatta daha ekonomik bir sonucu göstermektedir. Diğer çekirdek şekillerinde \%51 ve \% 56 daha ekonomik sonuç elde edilmiştir. Bu sonuçlara göre sandviç panellerin çekirdek şekili altıgen yapıldığı zaman çarpma yüküne karşı daha az malzeme kullanılmasının mümkün olacağı anlaşılmıştır.

\section{Yazarların Katkısı}

Yazarlar makaleye eşit oranda katkı sağlamıştır.

\section{Çıkar Çatışması Beyanı}

Yazarlar arasında herhangi bir çıkar çatışması bulunmamaktadır. 


\section{Araştırma ve Yayın Etiği Beyanı}

Yapılan çalışmada araştırma ve yayın etiğine uyulmuştur.

\section{Kaynaklar}

[1] Poyraz B. 2018. Kompozit malzeme üretiminde kullanılan poliesterlerin mekanik, termal ve kimyasal özelliklerine başlatıcı etkisinin incelenmesi. Gazi Üniversitesi Mühendislik-Mimarlık Fakültesi Dergisi, DOI: 10.17341/gazimmfd.416435.

[2] Kara Y., Akbulut H. 2017. Karbon elyaf takviyeli karbon nanotüp katkıl1 epoksi kompozit helisel yayların mekanik davranışları. Gazi Üniversitesi Mühendislik-Mimarlık Fakültesi Dergisi, 32 (2): 417-427.

[3] Asadi M., Vollaire A.C., Ashmead M.,Shirvani H. 2007. Experimental test and finite element modelling of pedestrian headform impact on honeycomb sandwich panel. 18th Engineering Mechanics Division Conference (EMD2007).

[4] Kılıçaslan C., Güden M., Odacı İ.K., Taşdemirci A. 2013. The impact responses and the finite element modeling of layered trapezoidal corrugated aluminumcore and aluminum sheet interlayer sandwich structures. Materials \& Design, 46: 121-133.

[5] Zhou G., Hill M.D. 2009. Impact damage and energy absorbing characteristics and residual inplane compressive strength of honeycomb sandwich panels. Journal of Sandwich Structures and Materials, 11: 329-356.

[6] Miller K., Joldes G., Lance D., Wittek A. 2007. Total Lagrangian explicit Dynamics finite element algorithm for computings of ttissue deformation. Communications In Numerical Methods In Engineering Commun. Numer. Meth. Engng, 23: 121-134.

[7] Belytschko T. 1976. A survey of numerical methods and computer programs for dynamic structural analysis. Nuclear Engineering and Design, 37: 23-34.

[8] Qiao H., Zhonglong L., Xueju S. 2007. Strain sensor-basedwireless measurement system for bridge. 10: 1322-1325.

[9] Tao M.Y.W. 2012. Finite Element Analysis of Cylinder Piston Impact Based on ANSYS/LSDYNA. Proceedings of 2012 International Conference on Mechanical Engineering and Material Science (MEMS 2012).

[10] Yüksel E.S.E.N., Ülker M. 2008. Malzeme ve geometrik özellikler bakımdan lineer olmayan çok katlı çelik uzay çerçevelerin optimizasyonu. Gazi Üniversitesi Mühendislik-Mimarlık Fakültesi Dergisi, 23 (2): 485-494.

[11] Doğru M.H. 2017. Tsai-wu kriteri kullanarak kompozit plakaların optimizasyonu için geliştirilen algoritma. Journal of the Faculty of Engineering and Architecture of Gazi University, 32 (3): 821829.

[12] Hallquist J.O. 2006. LS-DYNA Theory Manual. Livermore Software Technology Corporation, Livermore, California. 